\title{
ESCOLHENDO ESCOLHER: MOTIVOS E EXPECTATIVAS COM RELAÇÃO AO CASAMENTO
}

\author{
ELEGIR Y ELEGIR: MOTIVOS Y EXPECTATIVAS CON RESPECTO EL \\ MATRIMONIO
}

\author{
CHOOSING TO COOSE: REASONS AND EXPECTATIONS REGARDING \\ MARRIAGE
}

Alessandra Alves MACEDO ${ }^{1}$

RESUMO: A escolha do parceiro na vida adulta é considerada uma das únicas escolhas que é feita com liberdade, no entanto, carregada de expectativas sociais, pessoais, familiares e também motivadas por aspectos subjetivos (ANTON, 2002). Este trabalho busca descrever como no processo de escolha do cônjuge, aspectos familiares estão direta ou indiretamente envolvidos. Foi realizada entrevista semiestructurada a sete mulheres em seu primeiro ano de casamento. Os dados foram analisados conforme Análise de Conteúdo. Foram escolhidas três categorias: Família de Origem; Casamento; e Religião. As participantes possuem uma visão de como foi a escolha realizada por elas, com livre direito de escolha, mesmo assim, foram influenciadas pelas crenças e valores das famílias de origem. Em seu primeiro ano de união, demonstram boa experiência no casamento, e têm construído um relacionamento baseado em diálogos, apesar de "ditos e não ditos" da família de origem e sociedade.

PALAVRAS-CHAVE: Escolha do cônjuge, casamento, mitos familiares.

RESUMEN: La elección del compañero en la vida adulta es considerada una de las únicas opciones que se hace con libertad, sin embargo, cargada de expectativas sociales, personales, familiares y también motivadas por aspectos subjetivos (ANTON, 2002). Este trabajo busca describir cómo en el proceso de elección del cónyuge, aspectos familiares están directa o indirectamente involucrados. Se realizó una entrevista semiestructurada a siete mujeres en su primer año de matrimonio. Los datos fueron analizados según Análisis de Contenido. Se eligieron tres categorías: Familia de Origen; Matrimonio y Religión. Las participantes tienen una visión de cómo fue la elección realizada por ellas, con libre derecho de elección, sin embargo, fueron influenciadas por las creencias y valores de las familias de origen. En su primer año de unión, demuestran buena experiencia en el matrimonio, y han construido una relación basada en diálogos, a pesar de "dichos y no dichos" de la familia de origen y sociedad.

PALABRAS CLAVE: Elección del cónyuge, matrimonio, mitos familiares.

ABSTRACT: The choice of the partner in adult life is considered one of the only choices that is made with freedom, however, loaded with social, personal, family expectations

${ }^{1}$ Instituto de Atendimento, Ensino e Pesquisa do Indivíduo, Família e Comunidade - CAIFCOM. E-mail: lemacedo@gmail.com. 
and also motivated by subjective aspects (ANTON, 2002). This paper seeks to describe how in the process of choosing the spouse, family aspects are directly or indirectly involved. A semi-structured interview was conducted to seven women in their first year of marriage. Data were analyzed according to Content Analysis. Three categories were chosen: Family of Origin; Marriage; and Religion. The participants have a vision of how their choice was made, with free choice, yet they were influenced by the beliefs and values of the families of origin. In their first year of marriage, they demonstrate good experience in marriage, and have built a relationship based on dialogues, despite the "sayings and no sayings" of the family of origin and society.

KEYWORDS: Spouse's choice. Marriage. Family myths.

\section{Introdução}

A instituição casamento é uma das mais antigas da era civilizada e o processo de escolha do cônjuge é o primeiro passo para essa união, é o momento do nascimento do casal, sendo assim importante e determinante. Neste processo, muitas motivações e conceitos da família de origem interferem e influenciam nesse momento, mas, o casal tem atualmente a "liberdade" da escolha, visto que na idade antiga, os casamentos eram realizados por interesses políticos, religiosos, raciais e econômicos das famílias de origem dos noivos e a opinião e desejo deles, na maioria das vezes, não eram considerados. (YALOM, 2002).

Este trabalho procurou compreender com base em uma perspectiva sistêmica, na experiência de casais, em seu primeiro ano de casados, vivenciando a primeira fase do Ciclo Vital da Família, quais as principais motivações para a escolha do cônjuge, também se os mitos familiares transmitidos da família de origem foram mantidos e/ou resignificados e se estes, permearam e influenciaram no momento de escolha do cônjuge, já que, segundo Andolfi (1989), as experiências dos pais e as expectativas para os filhos possuem grande influência nas escolhas e desejos atuais do indivíduo. Investigar quais aspectos intrafamiliares estavam relacionados ao momento de escolha do cônjuge foi o principal objetivo desta investigação.

Foi escolhido o sexo feminino a partir do nosso trabalho clínico anterior com mulheres, com dificuldades na escolha do parceiro. Nesse sentido, consideramos importante aprofundar o tema.

\section{Diferenciação e pertencimento}


É característica do ser humano que somos seres sociais, no entanto, toda criança nasce indiferenciada em relação à sua família. Durante o desenvolvimento, para alcançar autonomia, começa a diferenciar-se.

A criança experimenta na família o pertencimento e a diferenciação: pertencimento, sentir-se membro da família, partilhar valores, crenças, mitos, segredos, regras; e a diferenciação como afirmação de sua singularidade, sua individuação e seu direito de pensar e expressar-se independentemente dos valores defendidos por sua família (MARTINS; RABINOVICH; SILVA, 2008).

As pessoas buscam um (a) companheiro (a), um modelo adulto de intimidade, assim como uma oportunidade da aquisição da individuação e do pertencimento, num processo dialético de fusão-individuação. É importante que cada indivíduo se separe de sua família de origem para formar a própria família. Quanto mais separados, mais estarão juntos, aumentando individualidade e intimidade (WHITAKER, 1995).

Minuchin (1990), ao conceituar família, coloca que esta dá a seus membros um sentido de pertencimento e um sentido de ser separado. Segundo Cerveny (2001), Família de origem, ligada aos conceitos de ascendência e descendência, pressupõe laços sanguíneos, inclui seus pais e os pais desses.

A maioria das pessoas irá se casar ou vivenciar algum tipo de união em algum momento de sua vida (MOSMANN; WAGNER; FÉRES-CARNEIRO, 2006). O conceito de "diferenciação do self", citado por Bowen (1979) equivale a maturação, identidade e individualidade.

\section{Mitos familiares}

Entende-se por mitos familiares um conjunto de crenças, conceitos e valores absorvidos pela família. E esses aspectos mantêm a estrutura e funcionamento familiar, que são transmitidos através de gerações e são compartilhados por todos os membros.

A expressão - estrutura e funcionamento - foi criada por Minuchin (1990), para designar os papéis familiares, implícitos e explícitos, que regem a família através de anos. É o que dá sentido à família: ditam regras, expectativas e padrões de conduta. $\mathrm{O}$ mito constitui, em sua essência, a própria concepção de mundo, da família, através da qual se cria a realidade familiar e o mapa do mundo individual. 
Para Cerveny (2001), mito familiar é uma narrativa construída pela família, que contém leituras da realidade e expressa convicções compartilhadas pelo grupo. Essa narrativa liga elementos dispersos como crenças, valores, tradições, transformando-se num conto organizado que serve como matriz de conhecimento. $\mathrm{O}$ mito familiar designa ainda as posições de cada um dentro do grupo e fornece modelos de conduta, conferindo significado e valor à existência.

Através dos mitos, interpreta-se o passado, compreende-se o presente e encontrase orientação para o futuro. $\mathrm{O}$ termo mito familiar foi primeiramente utilizado por a Ferreira (MIERMONT, 1994) para definir certas atitudes que se originam em alguns pensamentos do grupo familiar, garantindo uma coesão interna e uma proteção externa. “O mito familiar é, pois, um organizador que cumpre uma função homeostática que será tanto mais socilitada pelo grupo considerado quanto maior for o sofrimento, a dificuldade, a crise, a ameaça de transformar-se, de deslocar-se, ou inclusive de desaparecer" (MIERMONT, 1994, p. 389). Os mitos mantêm a coesão do grupo familiar através da delimitação de suas regras, papéis e funções a serem desempenhados por seus membros, valores e crenças compartilhados e compromissos de lealdade a serem cumpridos. Portanto, os mitos familiares se constituem em complexos modelos norteadores de conduta para os membros de uma família, não conscientes, transmitidos entre as gerações. Os mitos familiares podem ser repassados nas famílias através de seus rituais, compromissos de lealdade, padrões de comunicação, entre outros.

Os mitos familiares, podem ser vinculados ao termo "lealdade invisível", que implica atitude de acatamento à lei. Os pais esperam lealdade dos filhos e estes, como representantes dos avós cobram lealdades não resolvidas entre os pais e seus próprios pais. As famílias têm suas próprias leis, que fazem parte do padrão do sistema familiar herdado e desenvolvido pelos pais e filhos na atual família nuclear. Tal padrão cria uma rede de obrigações que, através de uma contínua troca de expectativas dentro do sistema de relações a que o indivíduo pertence, é responsável pela construção de um sistema de contabilidade.

As lealdades invisíveis abarcam em si muitos determinantes em sua configuração, que se referem à natureza da relação de pais e filhos e à intensidade e profundidade desses laços. (KROM, 2000). A transmissão do mito familiar caracteriza-se

por discursos complexos nos quais atitudes, comportamentos e mímicas dizem algo que as palavras calam. Tal transmissão se dá em um registro inconsciente; não se percebe exatamente o segredo, mas sim que o não-dito corresponde a 
alguma coisa, como uma palavra mal apagada em um texto escrito, e assim a transmissão do mito familiar pode se dar por suas formas particulares de censura - o segredo, o não-dito, o tabu (PRADO, 2000, p. 59).

Rosset (1999) ressalta que Mito é inconsciente, não é falado, mas é o que define a maior parte das situações da vida. É um objetivo irracional, disfuncional e inadequado ao momento e ao contexto, e o segredo é que o mantém. Os Mitos definem e preservam a identidade do sistema, e se transmitem transgeracionalmente.

O mito familiar é, portanto, retomando Prado (2000), uma realidade extremamente complexa, que tem como objetivo "tornar pensáveis situações extremamente saturadas em termos emocionais e de resolver possíveis contradições em planos diversos, descartando a busca de outras soluções"; sendo ainda "uma reconstrução contínua e uma ferramenta para o pensar" (p. 58).

O mito familiar é estruturante do funcionamento da família e do destino de seus integrantes [...] é um sistema de crenças compartilhadas pelos membros de uma família que, frequentemente, não é questionado por nenhum de seus membros e que trata de explicar - também encobrindo - aspectos conflitivos da história do grupo que constituem a identidade familiar. Os mitos fornecem as condições de pertencimento à família e instauram um sistema de valores que regulam a apreensão e a leitura da realidade interna e externa (MEYER, 1983-2002; ALMEIDA-PRADO, 1999; FERRARI, PIC-CININI, 2010).

O casamento assinala a construção e o início de uma nova família, assim sendo as pessoas utilizam-se de eixos para nortear a organização desse relacionamento e os mitos familiares envolvem todo o relacionamento.

Com o reconhecimento do sentimento do amor como base do matrimônio, surge a necessidade da realização amorosa e junto com isso vários mitos, como o Mito da Busca da Unidade Perdida (KROM, 2000, p. 56). O outro é o responsável pela realização dos sonhos do parceiro.

Andolfi (2002, p. 16) afirma que homens e mulheres herdam diferentes mitos a respeito do casamento. Enquanto as mulheres ainda se fascinam com as histórias da Cinderela, da Bela Adormecida, Branca de Neve entre outras, ou seja, que viverão felizes para sempre, para os homens há duas possibilidades míticas: ou será o "senhor do castelo" ou será nele aprisionado.

Emergem dessa ideia, mitos da felicidade associados ao casamento com base no amor romântico e representados pela célebre frase "casaram e viveram felizes para sempre..." Segundo Anton (2002) ainda hoje, século XXI para muitas pessoas o que 
justifica o casamento é esse amor apaixonado, idealizado, absoluto. E é o que também justifica o grande número de divórcios e recasamentos resultantes das frustrações vividas.

No entanto, a sociedade com o passar do tempo passou a denunciar esse mito vivido em contos de fada, pois não há príncipes nem princesas capazes de, ao se encontrarem, dissolver todos os sofrimentos passados, tornando-se, enfim, felizes para sempre; criou-se então o "Mito do casal XX", para suprir o vazio da insatisfação do mito "foram felizes para sempre". Neste novo mito se admitem conflitos que precisam ser resolvidos, mas o amor fala mais alto. Tenta-se se encaixar no casamento dito "perfeito", numa suposta aliança ideal. Para se encaixar neste mito, ambos os parceiros reprimem e negam seus conflitos, "mascaram ou projetam a responsabilidade sobre eles e o fazem isso inconscientemente". (ANTON, 2002, p. 70)

De acordo com Relvas (1996, p. 39), relacionado com este paradigma do "amor romântico" e com os mitos de felicidade, aparecem um conjunto de mitos associados ao casamento:

1. "O nosso amor, o desejo, a paixão, manter-se-á inalterável com o passar do tempo".

2. "O meu companheiro deverá ser capaz de antecipar todos os meus pensamentos, desejos e necessidades",

3. "Amar significa nunca me aborrecer com o meu companheiro".

4. "Amar significa estarmos sempre juntos".

5. "Se me amas de verdade esforçar-te-ás sempre por me agradar".

6. "Devemos estar sempre de acordo em qualquer tipo de assunto".

7. "Os níveis de sexo, carinho e compromisso presente na nossa relação não diminuirá nunca".

Todos estes fatores, além de provocarem uma grande decepção com o relacionamento, impedem a resolução dos conflitos e a adequada evolução da relação conjugal.

Já Pittman (1994) aborda alguns mitos do casamento, porém relacionados com o tema da infidelidade, que, segundo o autor, são enganosos, já que a monogamia é vista como ideal de casamento. 
Destaca também, que acordos no casamento são realizados acreditando na honestidade, intimidade e monogamia. A questão crucial do casamento, segundo aponta, é o comprometimento de cada um, a escolha que se faz diante de seu sistema de valores.

\section{Contratos implícitos}

Andolfi (2002) aponta que a instituição familiar transmite sistema de crenças e expectativas sobre o comportamento e relacionamentos. As ideias das familias de origem exercem uma influência muito forte sobre os contratos e sobre os modelos interativos que evoluem no curso do ciclo vital do casal. A partir do momento que duas pessoas optam por ser um casal, formam um novo sistema, estruturado a partir das experiencias de suas familias de origem, estruturando o padrão de funcionamento do casal.

A comunicação é uma das questões mais difíceis e mais importantes na relação de um casal. Segundo Rosset (2004, p. 21) “comunicação é um processo de dar e receber informação; é um processo verbal e não-verbal de fazer solicitações ao receptor; é um processo de interação; é o veiculo das manifestações observáveis da relação".

Ao iniciar uma relação, o casal vai contratando as formas de se relacionar as regras dessa relação. Segundo Rosset (2004), esse acerto vai sendo feito no desenrolar do relacionamento. Alguns itens são intencionais, outros surgem de acordo com as situações, podendo ser formalmente contratados, ou então sendo subliminares e implícitos. Os contratos implícitos são estes acordos de que nunca foram falados, mas, que estão presentes na família e se repercurtem no relacionamento de casal. Se estabelecem desde o início da relação, sem negociação e se consolidam sem que o outro perceba quando e como se deu início.

\section{Motivação para a escolha}

A motivação para a escolha ocorre por fatores diversos, como, alcançar uma vida de significado; satisfazer as necessidades pessoais de amor, aceitação, segurança, reconhecimento e interação. Muitos estudos foram desenvolvidos buscando apontar diferentes motivos envolvidos no processo de escolha do cônjuge, com base na literatura revisada, essa motivação se dá de forma, muitas vezes, inconsciente. (ANTON, 2012; 
DARE e PINCUS, 1978). Para Feinstein e Kripper (1992), os mitos estruturam a nossa consciência e apontam para a direção que se torna o nosso caminho.

O indivíduo não tem consciência do mito que vive em seu interior, frequentemente invisível, que o impulsiona de uma forma dinâmica em direção à escolha. Toda escolha é uma priorização. Consciente ou inconscientemente, os mitos estruturam a nossa consciência e exercem poderoso efeito sobre os sentimentos, pensamentos e atitudes, orientando nossas escolhas.

Existem diversos fatores que exercem grande influência no momento da escolha do cônjuge, como beleza, experiências pessoais, necessidades emocionais, valores, metas, crenças religiosas, escala de valores, fatores transgeracionais, todos, permeados pelos mitos (repetidos, transformados ou resignificados) da família de origem. Um estudo desenvolvido por Burgess e Locke (1945) procurou demonstrar que a influência dos familiares, sobretudo dos pais na escolha do cônjuge sobrepõe progressivamente fatores como religiosidade, passado familiar, tipo de namoro na adolescência, concepção de casamento e participação dos indivíduos na vida social.

Nos anos 50, Winch (1958) tentou demonstrar que as necessidades são recompensadas no decurso do processo de escolha do cônjuge através da procura de um parceiro cujas características de personalidade - e assim as necessidades, são opostas, mas complementares as do próprio. Aron (1991) procura confirmar a hipótese de os indivíduos procurarem num parceiro conjugal a possibilidade de reproduzir as relações que desde sempre estabeleceram com os seus pais.

O casamento, ainda é considerado como uma das tarefas da adultez para o bemestar do indivíduo (ERIKSON, 1994; BEE, 1997; CARTER, MACGOLDRICK, 2001; FÉRES-CARNEIRO, 2003; MORRIS, MAISTO, 2004). O momento de escolha do cônjuge é assunto de interesse de muitas pessoas e não somente dos que pretendem se casar, devido a seu relevante papel na estrutura da sociedade.

\section{Tipo de estudo}

É uma pesquisa qualitativa, de caráter descritivo exploratório.

A pesquisa aplica-se ao estudo das relações, das representações, das crenças, das percepções e das opiniões, produto das interpretações. Foi utilizado Análise de Conteúdo (BARDIN, 1977) para trabalhar o material que emergiram das entrevistas. 


\section{Participantes}

Foram entrevistadas sete mulheres, entre 22 e 35 anos de idade. As mulheres entrevistadas possuíam entre seis meses e um ano do primeiro casamento, não tinham filhos, nem de relacionamentos anteriores. Todas as entrevistadas são evangélicas ativas em suas congregações.

\section{Instrumento}

O instrumento usado foi uma entrevista semiestruturada, partindo de questionamentos básicos relacionados a escolha do cônjuge e opiniões e idéias da família de origem.

\section{Comitê de Ética em Pesquisa}

Após ter sido explicado a pesquisa para cada participante e mostrado a aprovação do projeto pelo Comitê de Ética em Pesquisa do CAIFCOM, a entrevistada assinou o Termo de Consentimento Livre e Esclarecido. Uma cópia desse termo ficou com a participante e outra com a pesquisadora.

\section{Resultados e discussão}

Para melhor compreensão dos resultados, se faz necessário contextualizar as mulheres entrevistadas.

Mulher 1: J, 35 anos de idade, casada há 9 meses. Ela é caçula de uma família de 2 filhos. O irmão mais velho já estava casado há 6 anos, tem dois filhos de 6 e 4 anos. Ela já estava fora de casa há mais de 10 anos. Família de origem religiosa, esperava um cônjuge da mesma religião e transmitiram a idéia de que o casamento é único para toda a vida. J. Não sonhava com casamento, acreditava ser uma possibilidade de vida. Priorizou sentimentos e religião.

Mulher 2: M, 28 anos, casada há 12 meses. Ela é a segunda de uma família de 3 filhos, sendo a única mulher, o irmão caçula, 29 anos ainda é solteiro. Família de origem religiosa, esperava um cônjuge da mesma religião, transmitiram a idéia que o casamento 
é único para toda a vida, e deveria sobrepor o sentimento, os pais fugiram para se casar. Sonhava em casar-se e não via em nenhuma hipótese a possibilidade de não realizar o sonho. Encontrou o cônjuge em um website de relacionamentos sociais. Priorizou sentimentos e religião.

Mulher 3: S. 26 anos, casada há 11 meses. Ela é terceira filha de uma família de 5 filhos. Sendo um homem e 4 mulheres. Apesar de já frequentarem lugares em comum, o primeiro contato foi on-line em um website de relacionamentos sociais. Nunca sonhou em se casar, e este era o medo dos pais, de que ela não se casasse. Via o casamento como uma prisão, o pedido foi dele, como um "ultimato", ou casariam, ou terminariam o relacionamento, decidiu se casar. Família de origem não é praticante de nenhuma religião, já ela e o cônjuge pertencem a mesma religião e foi uma prioridade na escolha. Contrário as opiniões da família, casou-se com uma pessoa de diferente etnia.

Mulher 4: P, 25 anos, casada há 8 meses. Filha caçula de uma família de 3 filhos. Outros irmãos casados e com filhos. Conhecia o cônjuge desde a infância, eram muito amigos, o relacionamento se deu por insistência dele. Ela não via o casamento como algo positivo, não sonhava em casar-se assim como também não sonha em ter filhos. Os pais "sonhavam" com um cônjuge da mesma religião, trabalhador e com boa conduta, e foi o que a motivou para a "aceitação".

Mulher 5: S, 24 anos, casada há 2 meses. Ela é filha caçula de uma família de 17 filhos. Outros irmãos casados. Família de origem religiosa e esperava que a escolha fosse da mesma religião. Conheceu o cônjuge em uma praia próxima, moravam na mesma cidade, mas, não pertenciam à mesma religião. Namoraram por 4 anos até tomarem uma decisão. A decisão dele em pertencer à mesma religião dela, procedeu a decisão do casamento. Não via o casamento como algo positivo, no entanto, hoje vê o companheirismo como principal vantagem do relacionamento. Priorizou sentimento e religião, segundo ela, os pais transmitiram a idéia que "princípios são regras que não podem ser mudadas".

Mulher 6: A, 22 anos, casada há 7 meses. Ela é primogênita de uma família de 2 filhas. Família de origem religiosa e esperava que a escolha fosse por um cônjuge da mesma religião. Conheceu o cônjuge na igreja que frequentava. Sonhava em casar, os pais apoiaram, mesmo ele sendo mais velho, mas, já estabilizado e com profissão definida. Priorizou religião, sentimento e estabilidade.

Mulher 7: B, 27 anos, casada há 11 meses. Ela é caçula de uma família de 3 filhos. Um irmão mais velho, casado e com uma filha. Irmã do meio casada, ainda sem filhos. 
Conheceu o cônjuge ainda criança, foi o primeiro namorado, depois terminaram, teve outros namorados, inclusive o ultimo, não pertencia à mesma religião. Foi alegria para a família quando terminou com este e voltou para o "primeiro amor", da mesma religião e com muitos amigos em comum. Priorizou religião, sentimento e amizade mútua.

Com a análise das entrevistas, elencamos três categorias: Família de Origem,

\section{Casamento e Religião.}

A primeira categoria intitulada Família de Origem, compreende as expectativas das famílias, as influências, a proximidade e as intromissões. A família de origem tem um papel relevante e exerce poder direta ou indiretamente, nesse momento do ciclo evolutivo vital.

Bowen (1979) afirma que muitas vezes, sem se dar conta, o indivíduo se casa com uma pessoa que expressa a recriação perfeita da própria família de origem. A partir desta perspectiva, a escolha do cônjuge é entendida como uma tentativa de busca de equilíbrio no relacionamento com a família de origem e de revisão de questões do passado que não estão bem resolvidas.

De forma geral, as entrevistadas afirmaram que suas famílias não se intrometeram em seus relacionamentos, e a escolha foi do próprio casal. Porém sabemos da influência indireta de suas famílias de origem, que ocorre por meio dos não ditos, dos implícitos. Em todas as famílias, a expectativa era que as filhas se casassem, apesar de algumas das entrevistadas afirmarem que não era a prioridade ou sonho delas.

Um aspecto que chama a atenção, demonstrando a influência indireta, é que a expectativa da maioria das famílias, com exceção de S.26, é que as filhas casassem com cônjuges que professassem a mesma religião. O que se vê claramente, em S. 24, que esperou que o cônjuge se convertesse à mesma religião para então decidir pelo casamento, apesar de todas afirmarem que não tiveram intromissão dos pais na escolha.

Verificou-se também que 5 das 7 entrevistadas já não moravam com os pais, parecendo ter claro e alegarem que já eram independentes emocionais e financeiramente, e tomavam suas decisões sem intromissão da família. B, 27 anos, apesar de morar com os pais, também alega que já era independente emocional e financeiramente dos pais.

A categoria denominada Casamento aborda como os cônjuges resolvem seus conflitos e como vivenciam o casamento.

Todas as entrevistadas relataram que os "contratos implícitos" foram conversados e combinados e restabelecidos à medida que encontraram dificuldades. A maioria delas relata que a abnegação das suas vontades é a maior dificuldade no início do 
relacionamento. Ao questionar o que se repete na família de origem, que tradições e rituais trouxeram, eles têm claro que repetem muita coisa de suas famílias, relatam que a religiosidade, comemorações de datas festivas, maneira de cozinhar e também alguns hábitos negativos, como desorganização e descontrole financeiro. Todas elas dizem que tentam repetir as coisas boas e rever as ruins.

A percepção do indivíduo sobre o casamento é socialmente construída (Barich e Bielby (1996). As entrevistadas demonstram que tem uma boa vivência em seus casamentos e o diálogo é frequente para estabelecer e restabelecer combinados e contratos.

A terceira categoria denominamos Religião pois, se mostrou a influência, ainda que de forma indireta, marcante em todas as entrevistadas. Observou-se inúmeros momentos em que, todas elas, demonstraram que uma das características primordiais para a escolha do cônjuge, segundo a família de origem, deveria ser, o pertencimento à mesma religião, demonstrando que no momento da escolha estão implicados fortemente os valores e legados do contexto familiar e social de cada um.

De modo geral, Anton (2012) afirma que nossa liberdade existe dentro de uma determinada faixa, cujos limites são marcados por condicionamentos e motivações inconscientes.

Todas as entrevistadas consideraram a religião (ou o relacionamento com Deus) um importante aspecto de sua vida pessoal e também relacionaram o sucesso do casamento ligado a este aspecto. Todas, são evangélicas ativas em suas congregações. Em concordância com Markstrom-Adams (1991), as entrevistadas também indicaram a existência de barreiras e subjetividade em relação ao namoro de um jovem evangélico com alguém de outra denominação.

Esses resultados demonstram que além da família, a religião exerce grande influencia, de forma direta ou indireta na escolha do cônjuge.

\section{Considerações finais}

A realização desta pesquisa, permitiu constatar e corroborar a literatura revisada que entre outras problemáticas, durante o processo de escolha, mesmo com a "liberdade" atual para este, suas motivações, ainda sofrem muita influência da família de origem, positivas e/ou negativas, direta e/ou indiretamente. 


\section{REFERÊNCIAS}

ALMEIDA PRADO, M. C. C. Destino e mito familiar: uma questão na família psicótica. Rio de Janeiro: Casa do Psicólogo, 1999

ANDOLFI, M. CLAUDIO, A.; SACCU, Carmine. O casal em crise. São Paulo: Summus, 1995.

ANDOLFI, Maurizio.; ANGELO, Claudio. Tempo e mito em psicoterapia familiar. Porto Alegre: Artes Medicas, 1989.

ANDOLFI, Maurizio. A crise do casal: uma perspectiva sistêmica relacional. Tradução: Lauro Kahl, Gioovanni Menegoz. Porto Alegre: Artmed, 2002.

ANTON, I. C. Homem e mulher: seus vínculos secretos. Porto Alegre: Artmed Editora, 2002.

ANTON, I. C. A escolha do cônjuge: um entendimento sistêmico e psicodinâmico. Porto Alegre: Artmed, 2012.

ARON, A.; ARON, E.; TUDOR, M.; NELSON, G. Close Relationships as Including Other in the Self. Journal of Personality and Social Psychology, 60 (2), 241-253, 1991.

BAGAROZZI, D. A.; ANDERSON, S. A. Mitos personales, matrimoniales y familiares: formulaciones teóricas y estratégias clinicas. Buenos Aires: Ediciones Paidós Ibérica, 1996.

BARDIN, L. Análise de conteúdo. Lisboa: Edições 70, 1977.

BARICH, R. R.; BIELBY, D. Rethinking Marriage: change and statibility in expectations. Journal of Family Issues, 17, 139-169, 1996.

BEE, H. O ciclo vital. Porto Alegre: Artes Médicas, 1997.

BOWEN, M. De la família ao individuo. Barcelona, España: Paidós, 1991. (Original publicado em 1979).

BOWLBY, J. Uma base segura: Aplicações clínicas da teoria do apego. Porto Alegre, RS: Artes Médicas, 1989.

BOWLBY, J. A natureza do vínculo. São Paulo: Martins Fontes. 2009.

BURGESS, E.; HARVEY, L. The Family. From Instituition to Companionship. New York: American Book Company. 1945.

CARRASCO, L. K. Por que casamos com quem casamos? Porto Alegre, EDIPUCRS, 2003. 
CARTER, B.; MCGOLDRICK, M. As mudanças no ciclo de vida familiar: uma estrutura para a terapia familiar. Porto Alegre: Artmed, 2001.

ERIKSON, E. H. (1994). Identity: youth and crisis. New York: WWNorton.

CERVENY, C. M. O. A família como modelo. São Paulo: Livro Pleno.2001.

DARE, C.; PINCUS, L. Secrets in the family. London: Faber and Faber, 1978.

FEINSTEIN, D. E.; KRIPPNER, S. Mitologia pessoal. São Paulo: Cultrix. 1992.

FÉRES-CARNEIRO, T. Construção e dissolução do laço conjugal. In: T. Féres-

Carneiro et al. Família e casal: arranjos e demandas contemporâneas. Rio de Janeiro:

PUC-Rio, 2003, p. 210-214.

FÉRES-CARNEIRO, T.; NETO, O. D. Construção e dissolução da conjugalidade:

padrões relacionais. Paidéia, v. 20, n. 46. Rio de Janeiro: Paidéia, maio-ago., p. 269-

$278,2010$.

FÉRES-CARNEIRO, T. Construção e dissolução do laço conjugal. In: FÉRES-

CARNEIRO T. et al. Família e casal: arranjos e demandas contemporâneas. Rio de Janeiro: PUC-Rio, 2003, p. 210-214.

FERRARI, A. G.; PICCININI, C. A. Função materna e mito familiar: evidências a partir de um estudo de caso. Ágora: Estudos em Teoria Psicanalítica, 13 (2), 243-257, 2010.

IMBER-BLACK, E. (Org.). Os segredos na família e na terapia familiar. Porto Alegre: Artes Médicas, 1994.

KROM, M. Família e mitos, prevenção e terapia: resgatando histórias. São Paulo: Summus, 2000.

MARKSTROM-ADAMS, C. Attitudes on dating, courtship, and marriage: perspectives on in-group versus out-group relationships by religious minority and majority adolescents. Family Relations, Minneapolis, v. 40, n. 1, p. 91-96, 1991.

MARTINS, E. M. A.; RABINOCICH, E. P.; SILVA, C. N. Família e o processo de diferenciação na perspectiva de Murray Bowen: um estudo de caso. Psicologia, USP, 19, 181-197, 2008.

MEYER, L. Família - dinâmica e terapia (uma abordagem psicanalítica). São Paulo: Casa do Psicólogo. (Trabalho original publicado em 1983), 2002.

MCGOLDRICK, M.; GERSON, R. Genogramas en la evaluacion familiar (5. ed.). Barcelona, España: Gedisa, 2005. (Original publicado em 1985).

MIERMONT, J. (Org.). Dicionário de terapias familiares. (C. A. Molina-Losa, Trad.). Porto Alegre, RS: Artes Médicas, 1994. (Original publicado em 1987). 
MINUNCHIN, S. Famílias: funcionamento e tratamento. J. A. Cunha, Trad. Porto Alegre: Artes Médicas, 1990

MORRIS, C. G.; MAISTO, A. A. Introdução à psicologia. São Paulo: Prentice Hall, 2004.

MOSMANN, C.; WAGNER A.; FÉRES-CARNEIRO, T. Qualidade conjugal: mapeando os conceitos. Ribeirão Preto: Paideia, 2006.

PITTMAN, F. Mentiras privadas. Porto Alegre: Artes Médicas, 1994

PRADO, M. do C. A. Destino e mito familiar: uma questão na família psicótica. São Paulo: Vetor, 2000.

RELVAS, A. P. O ciclo vital da família. Porto Alegre: Edições Afrontamento, 1996.

ROSSET, S. M. Compreensão relacional sistêmica dos mitos familiares. 1991.

Disponível em: $<$ http://www.srosset.com.br/textos/mitos_familiares.html $>$. Acesso em: 16 set. 2016.

ROSSET, S. M. O casal nosso de cada dia. Curitiba: Sol, 2004.

TRIVIÑOS, A. N. S. Introdução à pesquisa em Ciências Sociais: pesquisa qualitativa em educação. São Paulo, Atlas, 1994.

WHITAKER, A. Dançando com a familia. Porto Alegre: Artes Médicas, 1995.

WINCH, R.F. Mate-selection: a study of Complementary needs. New York: Harper and Row. 1958.

YALOM, M. A história da esposa: da virgem Maria a Madonna: O papel da mulher casada dos tempos bíblicos até hoje. Rio de Janeiro: Ediouro, 2002.

\section{Como referenciar este artigo}

MACEDO, Alessandra Alves. Escolhendo escolher: motivos e expectativas com relação ao casamento. Temas em Educ. e Saúde, Araraquara, v.13, n.2, p. 209-223, jul./dez. 2017. Disponível em: <https://doi.org/10.26673/rtes.v13.n2.jul-dez.2017.10159>. EISSN: 2526-3471.

Submetido em: 24/07/2017

Aprovado em: 20/10/2017 